\title{
Dexamethasone Modulates Rat Renal Brush Border Membrane Phosphate Transporter mRNA and Protein Abundance and Glycosphingolipid Composition
}

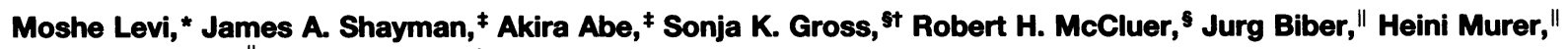 \\ Marius Lötscher," and Robert E. Cronin* \\ With the technical assistance of Shelly A. Scott* and Paul Wilson* \\ * Department of Internal Medicine, The University of Texas Southwestern Medical Center at Dallas and Department of Veterans Affairs \\ Medical Center, Dallas, Texas 75216; ${ }^{\ddagger}$ Department of Internal Medicine, University of Michigan Medical Center, Ann Arbor, Michigan \\ 48109; 'Department of Biochemistry, Eunice Kennedy Shriver Center for Mental Retardation, Waltham, Massachusetts 02254; and \\ "Institute of Physiology, University of Zurich, Zurich, Switzerland CH - 8057
}

\begin{abstract}
Glucocorticoids are important regulators of renal phosphate transport. This study investigates the role of alterations in renal brush border membrane (BBM) sodium gradient-dependent phosphate transport (Na-Pi cotransporter) mRNA and protein abundance in the dexamethasone induced inhibition of Na-Pi cotransport in the rat. Dexamethasone administration for $4 \mathrm{~d}$ caused a 1.5 -fold increase in the $V_{\max }$ of $\mathrm{Na}-\mathrm{Pi}$ cotransport $(1785 \pm 119 \mathrm{vs} .2759 \pm 375 \mathrm{pmol} / 5 \mathrm{~s}$ per mg BBM protein in control, $P<0.01$ ), which was paralleled by a 2.5 -fold decrease in the abundance of Na-Pi mRNA and Na-Pi protein. There was also a 1.7-fold increase in BBM glucosylceramide content $(528 \pm 63$ vs. $312 \pm 41 \mathrm{ng} / \mathrm{mg}$ BBM protein in control, $P<0.02)$. To determine whether the alteration in glucosylceramide content per se played a functional role in the decrease in Na-Pi cotransport, control rats were treated with the glucosylceramide synthase inhibitor, D-threo-1-phenyl-2-decanoyl-amino-3-morpholino-1propanol (PDMP). The resultant 1.5-fold decrease in BBM glucosylceramide content $(199 \pm 19$ vs. $312 \pm 41 \mathrm{ng} / \mathrm{mg} B B M$ protein in control, $P<0.02$ ) was associated with a 1.4-fold increase in Na-Pi cotransport activity ( $1422 \pm 73$ vs. $1048 \pm 85$ pmol/5 s per mg BBM protein in control, $P<0.01$ ), and a 1.5-fold increase in BBM Na-Pi protein abundance. Thus, dexamethasone-induced inhibition of Na-Pi cotransport is associated with a decrease in BBM Na-Pi cotransporter abundance, and an increase in glucosylceramide. Since primary alteration in BBM glucosylceramide content per se directly and selectively modulates BBM Na-Pi cotransport activity and $\mathrm{Na}-\mathrm{Pi}$ protein abundance, we propose that the increase in BBM glucosylceramide content plays an important role in mediating the inhibitory effect of dexamethasone on Na-Pi cotransport activity. (J. Clin. Invest. 1995. 96:207-216.) Key words: glucocorticoids • glucosylceramide - sphingomyelin - membrane fluidity $\cdot \mathrm{NaPi}-2$ protein

\section{Introduction}

Glucocorticoids are important regulators of renal phosphate transport. Glucocorticoid excess, e.g., Cushing's disease, and

\footnotetext{
${ }^{\dagger}$ Dr. Gross died on November 17, 1992.

Address correspondence to Moshe Levi, M.D., Department of Veterans Affairs Medical Center, 4500 South Lancaster Road (111G1), Dallas, Texas 75216. Phone: 214-372-7041; FAX: 214-372-7948.

Received for publication 5 July 1994 and accepted in revised form 16 March 1995.
}

The Journal of Clinical Investigation, Inc.

Volume 96, July 1995, 207-216 the administration of glucocorticoids to humans or experimental animals decreases tubular reabsorption of phosphate (1-3). In contrast, glucocorticoid deficiency after adrenalectomy increases tubular reabsorption of phosphate (4). The primary site of action of glucocorticoids to reduce phosphate reabsorption is the proximal tubule (5), an effect that is independent of endogenous parathyroid hormone activity (6). This inhibitory effect of glucocorticoids on renal tubular phosphate transport is expressed at the level of the proximal tubular apical brush border membranes $(7,8)$. The decrease in sodium gradientdependent phosphate transport (Na-Pi cotransport) ${ }^{1}$ results from a decrease in the $V_{\max }$ rather than a change in the affinity for phosphate (8). It is not known whether the decrease in the $V_{\max }$ reflects a decrease in the number of active $\mathrm{Na}-\mathrm{Pi}$ cotransport proteins or a change in the transport properties of existing $\mathrm{Na}-\mathrm{Pi}$ cotransport proteins.

Studies in freshly isolated proximal tubular cells or in primary cultured renal cells indicate that glucocorticoids have a direct and selective inhibitory effect on Na-Pi cotransport demonstrating that the effect is independent of concomitant alterations in renal hemodynamics and/or other phosphate transport regulatory hormones $(9-10)$. In cultured chick renal cells, dexamethasone inhibition of Na-Pi cotransport is blocked by inhibitors of transcription (actinomycin D) and translation (cycloheximide) (10). The nature of the inhibitory proteins produced by dexamethasone is unknown. They could inhibit of $\mathrm{Na}-\mathrm{Pi}$ cotransport by causing a decrease in the abundance of $\mathrm{Na}-\mathrm{Pi}$ cotransport proteins. Alternatively, they might alter membrane lipid composition, since alterations in brush border membrane lipid content or lipid dynamics also regulate $\mathrm{Na}-\mathrm{Pi}$ cotransport (11). Thus, inhibitors of RNA and protein synthesis could block dexamethasone induced inhibition of $\mathrm{Na}-\mathrm{Pi}$ cotransport through an effect on the synthesis and content of specific membrane lipids.

Recently the cDNA for a Na-Pi cotransport system of rat kidney cortex ( $\mathrm{NaPi}-2)$ has been identified by expression cloning (12). Using polyclonal antibodies raised against this renal $\mathrm{Na}-\mathrm{Pi}$ cotransport system, and using the polymerase chain reaction after reverse transcription of mRNA in microdissected nephron segments, we recently demonstrated that $\mathrm{NaPi}-2-\mathrm{re}-$ lated mRNA and protein is expressed in the brush border membranes of the proximal tubules in rat kidney (13).

The present study investigates $(a)$ whether the inhibitory effect of dexamethasone on Na-Pi cotransport is mediated by changes in Na-Pi cotransport mRNA and protein abundance

1. Abbreviations used in this paper: BBM, brush border membrane; NaPi cotransport, sodium gradient-dependent phosphate transport. 
and/or a change in brush border membrane lipid composition and lipid dynamics, and $(b)$ whether the alteration in brush border membrane lipid composition per se can directly modulate Na-Pi cotransport activity.

\section{Methods}

\section{Experimental animals}

The experiments were performed in male Sprague Dawley rats weighing 150-200 grams (Harlan Industries, Indianapolis, IN). Before study, the animals were stabilized on the control diet $(0.6 \% \mathrm{Pi})$ for $5 \mathrm{~d}$ in metabolic balance cages. The rats were then treated with dexamethasone, 100 $\mu \mathrm{g} / 100$ gram body weight, or vehicle (deionized water), administered subcutaneously once a day for four consecutive days. On the fourth day, a 24-h urine collection was obtained. On the fifth day, the rats were anesthetized with sodium pentobarbital, blood was obtained from the inferior vena cava, and the kidneys rapidly removed and placed in an ice-cold buffer. Blood and urine samples were analyzed for inorganic phosphate by the method of Fiske and Subbarow (14), and for creatinine by a creatinine autoanalyzer (Creatinine II Analyzer, Beckman, Fullerton, CA). Total urinary phosphate excretion and tubular reabsorption of phosphate were calculated by standard clearance formulae.

In experiments designed to determine the role of alteration in glucosylceramide content per se in the regulation of Na-Pi cotransport ( see Results), control animals were treated with DL-threo-1-phenyl-2-decanoylamino-3-morpholino-1-propanol (PDMP), an inhibitor of glucosylceramide synthase (15-16). Since previous studies have demonstrated that the circulating plasma levels of PDMP are prolonged in the presence of the cytochrome P450 inhibitor, piperonyl butoxide (16), the butoxide solution was administered before injection of PDMP. The piperonyl butoxide was prepared by dissolution in corn oil at a concentration of $150 \mathrm{mg} / \mathrm{ml}$ oil. On the first day of treatment, the butoxide solution was administered intraperitoneally $4 \mathrm{~h}$ before PDMP treatment; on days 2 to 4 of treatment, it was administered just before the PDMP injection. PDMP was prepared as an emulsion with the detergent Myrj 52 in normal saline, buffered with sodium acetate. The final concentrations were PDMP $6 \mathrm{mg} / \mathrm{dl}$, Myrj $5212 \mathrm{mg} / \mathrm{dl}$, and sodium acetate $8 \mathrm{mg} / \mathrm{dl}$. The PDMP was given intraperitoneally as a dose of $100 \mathrm{mg} / \mathrm{kg}$ body weight.

\section{Brush border membrane isolation}

The kidneys were placed in an ice-cold homogenizing buffer consisting of $300 \mathrm{mM}$ mannitol, $5 \mathrm{mM}$ EGTA, $0.1 \mathrm{mM}$ PMSF, $16 \mathrm{mM}$ HEPES, $\mathrm{pH} 7.50$ with Tris. Thin slices were cut from the superficial cortex and homogenized with a Polytron homogenizer. Brush border membrane (BBM) vesicles were isolated from the resulting homogenate by differential centrifugation and $\mathrm{Mg}^{2+}$ precipitation, as previously described (17). To minimize the potential day-to-day variations in BBM isolation procedure on the resultant measurements, each day BBM from control and dexamethasone-treated rats were isolated simultaneously. For each BBM sample the kidneys from three rats from each experimental group were pooled $(n=1)$. A total of 36 rats were studied in each group, resulting in $n=12$ BBM samples for each experimental group. The final BBM pellet was resuspended in a $300 \mathrm{mM}$ mannitol, $16 \mathrm{mM}$ Hepes, $10 \mathrm{mM}$ Tris, pH 7.50 buffer and was aliquoted for simultaneous measurements of $(a)$ enzyme activity, $(b)$ transport activity, $(c)$ protein electrophoresis and Western blotting, $(d)$ lipid composition, and $(e)$ lipid fluidity.

\section{Brush border membrane enzyme activity measurements}

The purity of each BBM preparation was determined by measurement of membrane-bound specific enzyme activity, including leucine aminopeptidase (apical marker) and $\mathrm{Na}, \mathrm{K}$-ATPase (basolateral marker) in cortical homogenate and in BBM fractions as previously described (18). Enzyme activities were expressed as $\mu \mathrm{mol} / \mathrm{h}$ per $\mathrm{mg}$ cortical homogenate or BBM protein. Enrichment (specific activity in BBM/specific activity in homogenate) and recovery (total activity in BBM/total activ- ity in homogenate) were determined using the above enzymes as markers of apical and basolateral membranes. Protein was determined by the method of Lowry et al (19) using crystalline BSA as standard.

\section{Brush border membrane transport measurements}

Transport measurements were performed in freshly isolated BBM vesicles by radiotracer uptake followed by rapid millipore filtration. To measure $\mathrm{Na}^{+}$gradient-dependent ${ }^{32} \mathrm{Pi}$ uptake (Na-Pi cotransport), 10 $\mu \mathrm{l}$ of BBM preloaded in an intravesicular buffer of $300 \mathrm{mM}$ mannitol, $16 \mathrm{mM}$ Hepes, $10 \mathrm{mM}$ Tris, $\mathrm{pH} 7.50$ was vortex mixed at $25^{\circ} \mathrm{C}$ with $40 \mu \mathrm{l}$ of an extravesicular uptake buffer of $150 \mathrm{mM} \mathrm{NaCl}, 100 \mu \mathrm{M}$ $\mathrm{K}_{2} \mathrm{H}^{32} \mathrm{PO}_{4}, 16 \mathrm{mM}$ Hepes, $10 \mathrm{mM}$ Tris, pH 7.50. Uptake after $5 \mathrm{~s}$ (representing initial linear rate) was terminated by an ice-cold stop solution which consisted of $135 \mathrm{mM} \mathrm{NaCl}, 10 \mathrm{mM} \mathrm{Na}_{2}$ arsenate, 16 $\mathrm{mM}$ Hepes, $10 \mathrm{mM}$ Tris, $\mathrm{pH}$ 7.50. All uptake measurements were performed in triplicate, and uptake was calculated on the basis of specific activity determined in each experiment and expressed as $\mathrm{pmol}{ }^{32} \mathrm{Pi} / 5 \mathrm{~s}$ per mg BBM protein.

To determine if the differences in Na-Pi cotransport were specific for $\mathrm{Pi}, \mathrm{Na}^{+}$gradient-dependent glucose and proline uptake were also measured. BBM vesicles were preloaded with the $300 \mathrm{mM}$ mannitolHEPES-Tris ( $\mathrm{pH} 7.50$ ) intravesicular buffer, and the uptake solution consisted of $150 \mathrm{mM} \mathrm{NaCl}$ and either $100 \mu \mathrm{M} \mathrm{D}-\left[{ }^{3} \mathrm{H}\right]$ glucose, or 100 $\mu \mathrm{M} \mathrm{L}-\left[{ }^{3} \mathrm{H}\right]$ proline and HEPES-Tris, $\mathrm{pH}$ 7.50. Uptake was terminated by the stop solution, which consisted of $150 \mathrm{mM} \mathrm{NaCl}, 0.25 \mathrm{M}$ phloridzin, and Hepes-Tris added to $\mathrm{pH} 7.50$.

\section{Brush border membrane protein electrophoresis and Western blots}

BBM were denatured for $2 \mathrm{~min}$ at $95^{\circ} \mathrm{C}$ in $2 \%$ SDS, $10 \%$ glycerol, 1 $\mathrm{mM}$ EDTA, $95 \mathrm{mM}$ Tris/ $\mathrm{HCl}, \mathrm{pH} 6.8$ (final concentrations) and $40 \mu \mathrm{g}$ BBM protein per lane were electrophoresed on $10 \%$ polyacrylamide gels according to Laemmli (20), as previously described (21). After electrophoretic transfer onto nitrocellulose membranes (BA83; Schleicher \& Schuell, Keene, $\mathrm{NH}$ ) Western blots were performed using antisera against $\mathrm{NaPi}-2$ and $5^{\prime}$-nucleotidase at dilutions of 1:4,000 and $1: 5,000$, respectively. Production of polyclonal antibodies against $\mathrm{COOH}$ - and $\mathrm{NH}_{2}$-terminal synthetic peptide of a recently cloned $\mathrm{Na}-\mathrm{Pi}$ cotransport system of rat kidney cortex ( $\mathrm{NaPi}-2)(12)$ has been recently described (13). Polyclonal antibodies against renal ecto-5'-nucleotidase were obtained against the purified enzyme as described and characterized (22). Primary antibody binding was visualized using goat antirabbit IgG conjugated to alkaline phosphatase (Bio Rad Laboratories, Richmond, CA) and quantified by densitometry. Prestained molecular weight marker proteins (Bio Rad Laboratories) were run in parallel.

Brush border membrane lipid composition measurements

Lipids from brush border membrane were extracted by the method of Bligh and Dyer (23), as we have previously described (17-18).

To determine free cholesterol content. An aliquot of the lipid extract was injected into a $530 \mu \mathrm{m} \mathrm{50 \%} \mathrm{phenylmethyl} \mathrm{silicone} \mathrm{column} \mathrm{in} \mathrm{a}$ Hewlett Packard model 5890 gas chromatograph with a flame ionization detector, run isothermally at $280^{\circ} \mathrm{C}$, with coprostanol serving as an internal standard. Area ratios were completed with a Hewlett-Packard 3392A integrator, and cholesterol was expressed as nmol per $\mathrm{mg}$ brush border membrane protein (11).

To determine individual phospholipid polar head group species. An aliquot of the lipid extract was applied to thin layer chromatography plates (Silica Gel 60, E. Merck, Darmstadt, FRG) and individual phospholipids including sphingomyelin, phosphatidylcholine, phosphatidylethanolamine, phosphatidylserine, and phosphatidylinositol were separated by a two-dimension solvent system (24), as we have previously described (17-18). Phospholipid content in total and individual phospholipids was determined by measuring phosphorus content by the method of Ames and Dubin (25).

To determine the glycosphingolipid composition. An aliquot of the lipid extract was evaporated to dryness and subjected to alkaline methanolysis. Briefly, the dried lipids were dissolved in $2 \mathrm{ml}$ of chloroform. 
The reaction was started by adding $1 \mathrm{ml}$ of $0.21 \mathrm{~N}$ sodium hydroxide in methanol, continued for $1 \mathrm{~h}$ at $37^{\circ} \mathrm{C}$ and terminated by adding 0.8 $\mathrm{ml}$ of $0.2 \mathrm{M}$ acetic acid. The resultant mixture was centrifuged for 5 $\min$ at 800 grams. The upper layer was removed. The lower layer was washed with $1 \mathrm{ml}$ of methanol plus $0.8 \mathrm{ml}$ of water. After the same centrifugation, the lower layer was transferred into another glass tube and dried under a stream of nitrogen gas. The lipids were then chromatographed on high performance thin layer chromatography plates (HPTLC, E. Merck 5641): glucosylceramide was separated with a solvent system consisting of chloroform:methanol:water $(65: 25: 4)$ on plates which were pretreated with $2.5 \%$ borax in methanol:water $(1: 1)$. The lipid bands were visualized by impregnating the plates with a modified charring reagent ( 100 grams of $\mathrm{CuSO}_{4} 5 \mathrm{H}_{2} \mathrm{O}$ in conc. $\mathrm{H}_{3} \mathrm{PO}_{4} /$ water/ methanol (100:750:400) (16). The charred TLC plates were scanned with a video densitometer. The glucosylceramide bands were quantitated by comparing the density of each spot with the density of the corresponding standard curve.

To determine the glycosphingolipid molecular species. The lipid extracts were dissolved in chloroform:methanol, 2:1, vol/vol, and partitioned into lower and upper phase GSL according to Folch et al. (26). The lower phase GSL were put over a Unisil column and eluted with acetone:methanol, 9:1, vol/vol. After alkaline hydrolysis the samples were dried and perbenzoylated in $10 \%$ benzoyl chloride in pyridine for $16 \mathrm{~h}$ at $37^{\circ} \mathrm{C}$. The benzoylated glycolipids were then dissolved in carbon tetrachloride, and injected onto a silica gel column (Zipax, E.I. Dupont, Wilmington, DE, $2.1 \mathrm{~mm} \times 50 \mathrm{~cm}$ ) and eluted with a 13-min linear gradient of $1-20 \%$ dioxane in hexane with a flow rate of $2 \mathrm{ml} / \mathrm{min}$ (27). Absorption was read at $230 \mathrm{~nm}$. The individual GSL peaks were integrated by a Dynamax system on a Macintosh SE computer.

\section{Brush border membrane lipid fluidity measurements}

BBM fluidity was determined by the steady-state and time-resolved fluorescence measurements of (a) 1,6-diphenyl-1,3,5,-hexatriene (DPH), and (b) 6-dodecanoyl-2-diethylaminonaphthalene (Laurdan) (Molecular Probes, Eugene, OR). The steady-state emission spectra of Laurdan was measured in a spectrofluorometer (SLM 4800C, Urbana, II). Excitation wavelength was $340 \mathrm{~nm}$, and emission was measured at $440 \mathrm{~nm}$ and $490 \mathrm{~nm}$. In phospholipid vesicles and in BBM the emission maximum for Laurdan is $440 \mathrm{~nm}$ in the gel phase and $490 \mathrm{~nm}$ in the liquid-crystalline phase (28-29). The emission spectra of Laurdan is quantitated by the generalized polarization (GP)

$$
G P_{\text {Laurdan }}=\frac{I_{440}-I_{490}}{I_{440}+I_{490}}
$$

where $I_{440}$ and $I_{490}$ are the emission intensities at 440 and $490 \mathrm{~nm}$, respectively (28-29).

The steady-state anisotropy of DPH $\left(r_{\mathrm{DPH}}\right)$ was measured in the same spectrofluorometer equipped with excitation and emission polarizers. Excitation wavelength was $360 \mathrm{~nm}$ and emission was viewed through a KV $399 \mathrm{~nm}$ filter. $r_{\mathrm{DPH}}$ is determined by:

$$
r_{\mathrm{DPH}}=\frac{I_{\mathrm{II}}-I_{\mathrm{I}}}{I_{\mathrm{II}}+2 I_{\mathrm{I}}}
$$

where $I_{I I}$ and $I_{I}$ represent the intensities of the parallel and perpendicular components of the emission respectively (17).

The fluorescence lifetimes of DPH and Laurdan were measured with use of a photon counting multifrequency phase and modulation spectrofluorometer (ISS K2, Urbana, IL) using the $351 \mathrm{~nm}$ excitation line of an argon ion laser (30). The dynamic polarization of DPH was also measured with use of a multifrequency differential phase and modulation spectrofluorometer using the $351 \mathrm{~nm}$ excitation line of an argon ion laser. The time-resolved fluorescence data were analyzed with Globals Unlimited software (Laboratory for Fluorescence Dynamics, University of Illinois at Urbana-Champaign, IL) (31).

\section{RNA isolation}

Thin slices were cut at $4^{\circ} \mathrm{C}$ from the superficial cortex and homogenized with Polytron in a $4 \mathrm{M}$ guanidium thiocyanate, $25 \mathrm{mM}$ sodium citrate,
$\mathrm{pH} 7.0 ; 0.5 \%$ sarcosyl, $0.1 \mathrm{M}$ 2-mercaptoethanol denaturation solution. Sequentially, 0.1 vol $2 \mathrm{M}$ sodium acetate, $\mathrm{pH} 4.0,1$ vol water-saturated phenol, and 0.2 vol chloroform-isoamyl alcohol mixture (49:1) were added to the homogenate. Total RNA was isolated as previously described (32), and resuspended in water treated with diethyl pyrocarbonate (DEPC). Absorbance at 260 and $280 \mathrm{~nm}$ were obtained to quantify and asses the purity of the RNA fraction.

\section{Formaldehyde agarose gel electrophoresis and Northern blot analysis}

After denaturation of RNA samples in formaldehyde, $20 \mu \mathrm{g}$ total RNA per lane was size fractionated using $0.66 \mathrm{M}$ formaldehyde, $1 \%$ agarose (final concentration) gels (BioRad Laboratory). RNA size standards (GIBCO BRL, Gaithersburg, MD) were run in parallel. After electrophoresis the gel was placed onto a vacuum-blotting device (BioRad Laboratories) and vacuum of $60 \mathrm{~cm} \mathrm{H}_{2} \mathrm{O}$ was applied for $4 \mathrm{~h}$ using $20 \times$ SSC ( $3 \mathrm{M} \mathrm{NaCl}, 0.3 \mathrm{M} \mathrm{Na}_{3}$ citrate, pH 7.0) as blotting buffer, which resulted in complete transfer of RNA. The RNA was blotted onto GeneScreen Plus nylon membranes (NEN/DuPont, Boston, MA) and the RNA was immobilized by irradiation with ultraviolet (U.V.) light (UV crosslinker; BioRad Laboratories). Prehybridization $\left(4 \mathrm{~h}\right.$ at $\left.42^{\circ} \mathrm{C}\right)$ and hybridization $\left(18 \mathrm{~h}\right.$ at $42^{\circ} \mathrm{C}$ ) of the RNA blots were performed with a buffer $\left(250 \mu \mathrm{l} / \mathrm{cm}^{2}\right)$ consisting of $5 \times \operatorname{SSPE}(0.75 \mathrm{M} \mathrm{NaCl}, 50 \mathrm{mM}$ $\mathrm{NaH}_{2} \mathrm{PO}_{4}, 5 \mathrm{mM}$ EDTA, pH 7.40), 5× Denhardt's solution, [0.1\% Ficoll $400,0.1 \%$ polyvinylpyrrolidone, $0.1 \%$ BSA (fraction V)], $0.1 \%$ SDS, $100 \mu \mathrm{g} / \mathrm{ml}$ denatured salmon sperm DNA, and $50 \%$ deionized formamide as previously described (33). cDNA probes of NaPi-2 (12), $\beta$-Actin (34) and GAPDH (35), all full length, were labeled by random priming (Pharmacia Biotech Inc., Piscataway, NJ) using $\left[\alpha-{ }^{32} \mathrm{P}\right] \mathrm{dCTP}$ (NEN-DuPont, Boston, MA). After hybridization, the blots were washed twice for $15 \mathrm{~min}$ each time in $2 \times$ SSPE, $0.1 \%$ SDS at room temperature, twice for $15 \mathrm{~min}$ each time in $0.1 \times$ SSPE, $0.1 \%$ SDS at $37^{\circ} \mathrm{C}$, and twice for $15 \mathrm{~min}$ each time in $0.1 \times$ SSPE, $0.1 \%$ SDS at $50^{\circ} \mathrm{C}$. Autoradiography was performed at $-70^{\circ} \mathrm{C}$ with NEN-DuPont Reflection film using a DuPont intensifying screen (NEN-DuPont). Membranes were stripped $\left(0.1 \times \mathrm{SSC}, 0.1 \%\right.$ SDS at $95^{\circ} \mathrm{C}$ for $\left.5 \mathrm{~min}\right)$ before another hybridization was performed. mRNA levels for NaPi-2 was quantitated by densitometry and normalized to the density of the corresponding GAPDH and $\beta$-actin mRNA.

\section{Data analysis}

The data are expressed as the mean \pm SE. The statistical significance of the results between samples obtained from control and experimental rats was determined by the unpaired students $t$ test or one way analysis of variance with Student-Newman Keul analysis for multiple comparisons. Significance was accepted at the $P<0.05$ level.

\section{Results}

The effect of dexamethasone on urinary phosphate excretion. Dexamethasone administration caused a significant increase in urinary excretion of $\mathrm{Pi}$ and a decrease in the tubular reabsorption of $\mathrm{Pi}$. These occurred despite a decrease in serum Pi concentration (Table I).

The effect of dexamethasone on BBM enzyme activity. Dexamethasone had no effect on the activity of the apical membrane enzyme marker leucine aminopeptidase. Enrichment and recovery of leucine aminopeptidase was similar in BBM isolated from control and dexamethasone-treated rats. As previously described (36), dexamethasone caused an increase in the activity of the basolateral membrane enzyme marker Na,K-ATPase. Enrichment and recovery of $\mathrm{Na}, \mathrm{K}-\mathrm{ATPase}$ was, however, minimal and similar in BBM isolated from control and dexamethasonetreated rats (Table II). BBM isolated from control and dexamethasone-treated rats were, therefore, highly and similarly purified. 
Table I. The Effect of Dexamethasone on Serum Phosphate and Urinary Phosphate Excretion

\begin{tabular}{lccc}
\hline & $\mathrm{S}_{\mathrm{Ri}}$ & \multicolumn{1}{c}{$\mathrm{U}_{\mathrm{Pi}} \times \mathrm{V}$} & \multicolumn{1}{c}{$\mathrm{TRPi}$} \\
\hline$m g / d l$ & $m g / 24 h$ & $\%$ \\
Control & $7.9 \pm 0.4$ & $22.4 \pm 3.6$ & $86.5 \pm 1.8$ \\
Dexamethasone & $6.6 \pm 0.4^{*}$ & $54.3 \pm 13.0^{*}$ & $44.8 \pm 5.3^{\ddagger}$ \\
\hline
\end{tabular}

The data are expressed as the mean $\pm \mathrm{SE}$ for 6 rats in each group. ${ }^{*} P$ $<0.05,{ }^{\ddagger} P<0.001$ by unpaired t-test. $S_{P i}$, serum phosphate concentration; $U_{P i} \times V$, urinary phosphate excretion; $T R P i$, tubular reabsorption of phosphate defined as $1-\mathrm{C}_{\mathrm{Pi}} / \mathrm{C}_{\mathrm{Cr}} ; \mathrm{C}_{P i}$, clearance of phosphate; $C_{C_{r}}$, clearance of creatinine.

The effect of dexamethasone on BBM transport activity. Dexamethasone caused a significant decrease in BBM Na-Pi cotransport activity. The decrease in Na-Pi cotransport was selective as dexamethasone did not cause changes in Na-glucose or Na-proline cotransport activities (Fig. 1). The decrease in $\mathrm{Na}-\mathrm{Pi}$ cotransport in dexamethasone-treated rats was not caused by a faster dissipation of the $\mathrm{Na}^{+}$gradient via the enhanced activity of the $\mathrm{Na} / \mathrm{H}$ antiporter, as, in the presence of $3 \mathrm{mM}$ amiloride, Na-Pi cotransport was still significantly decreased $\left(954 \pm 22\right.$ in dexamethasone vs. $1386 \pm 123 \mathrm{pmol}{ }^{32} \mathrm{Pi} / 5 \mathrm{~s}$ per mg BBM protein in control, $P<0.01$ ).

The effect of dexamethasone on BBM Na-Pi cotransport kinetics. Kinetics of $\mathrm{Na}-\mathrm{Pi}$ cotransport in the presence of 150 $\mathrm{mM} \mathrm{NaCl}$ and as a function of extravesicular Pi ranging from 25 to $800 \mu \mathrm{M}$ Pi indicated that dexamethasone caused a decrease the $V_{\max }$ of $\mathrm{Na}-\mathrm{Pi}$ cotransport, whereas, dexamethasone did not change the affinity for Pi (Fig. 2). Similarly, kinetics of Na-Pi cotransport in the presence of $800 \mu \mathrm{M} \mathrm{Pi}$ and as a function of extravesicular $\mathrm{NaCl}$ ranging from 0 to $150 \mathrm{mM}$ $\mathrm{NaCl}$ indicated that dexamethasone caused a decrease in the $V_{\max }$ of Na-Pi cotransport, whereas, dexamethasone did not change the affinity for $\mathrm{Na}$, or the stoichiometry for $\mathrm{Na}-\mathrm{Pi}$ cotransport (data not shown).

Table II. The Effect of Dexamethasone on Brush Border Membrane Enzyme Activity, Enrichment, and Recovery

\begin{tabular}{lcc}
\hline & Control & Dexamethasone \\
\hline Leucine Aminopeptidase & & \\
CH & $2.10 \pm 0.07$ & $1.95 \pm 0.13$ \\
BBM & $22.44 \pm 0.88$ & $20.24 \pm 0.57$ \\
ENR & $10.7 \pm 0.4$ & $10.7 \pm 0.9$ \\
REC & $34.8 \pm 1.9$ & $40.6 \pm 2.8$ \\
Na,K-ATPase & & \\
CH & $25.8 \pm 0.9$ & $34.2 \pm 1.1^{*}$ \\
BBM & $29.8 \pm 1.2$ & $41.1 \pm 1.4 *$ \\
ENR & $1.2 \pm 0.1$ & $1.2 \pm 0.1$ \\
REC & $3.8 \pm 0.2$ & $4.6 \pm 0.2$ \\
& & \\
\hline
\end{tabular}

The data are expressed as the mean \pm SE for $12 \mathrm{BBM}$ preparations in each group. $* P<0.001$ by unpaired $t$ test. The enzyme activities are expressed as $\mu \mathrm{mol} / \mathrm{h}$ per $\mathrm{mg}$ cortical homogenate $(\mathrm{CH})$ or brush border membrane $(B B M)$ protein. ENR (enrichment) and REC (recovery) were determined as indicated in Methods.

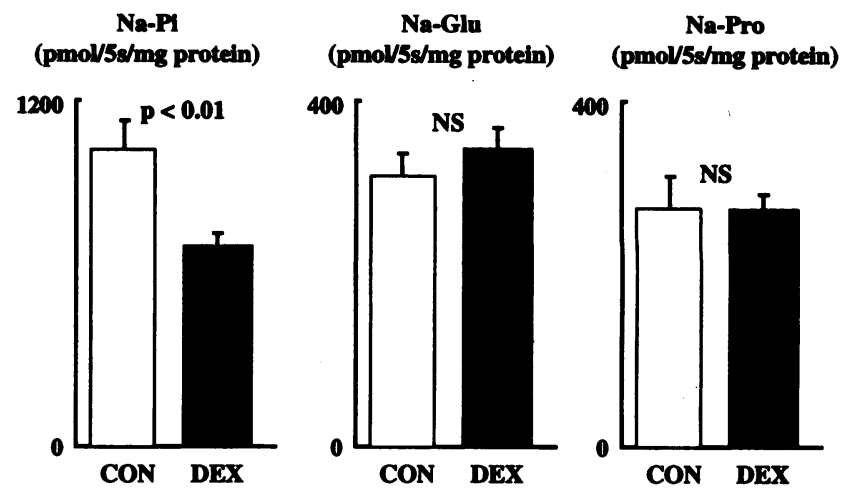

Figure 1. Effect of dexamethasone on BBM sodium gradient-dependent phosphate $(\mathrm{Na}-\mathrm{Pi})$, glucose $(\mathrm{Na}-\mathrm{Glu})$, and proline ( $\mathrm{Na}-\mathrm{Pro})$ transport activity. The data are expressed as the mean \pm SE for $12 \mathrm{BBM}$ in each group.

The effect of dexamethasone on renal cortical Na-Pi mRNA abundance. To determine if the $V_{\max }$ of Na-Pi cotransport was associated with a decrease in Na-Pi mRNA, RNA isolated from control and dexamethasone treated rats were analyzed by Northern blots. As illustrated in Fig. 3, NaPi-2 mRNa shown by a 2.6-kb transcript is significantly decreased in dexamethasone treated rats. Ethidium bromide staining of the gel and rehybridization of the Northern blot with GAPDH or $\beta$-actin cDNA probes indicate that the decrease in $\mathrm{NaPi}-2$ mRNA abundance is not due to differences in RNA loading on the gels. The abundance of $\mathrm{NaPi}-2$ mRNA relative to GAPDH or $\beta$-actin mRNA, determined by densitometric analysis, indicates that NaPi- 2 mRNA is decreased by 2.5 -fold in dexamethasone treated rats.

The effect of dexamethasone on BBM Na-Pi cotransporter abundance. To determine if the dexamethasone induced decrease in the $V_{\max }$ of $\mathrm{Na}-\mathrm{Pi}$ cotransport was associated with a decrease in Na-Pi cotransporter abundance, BBM isolated from control and dexamethasone treated rats were analyzed by Western blots using the anti ( $\mathrm{NaPi}-2)$-antiserum. As illustrated in Fig. 4, a strong reaction with a $80-90-\mathrm{kD}$ protein bands was observed in BBM from control and dexamethasone rats. Densitometric analysis of the reaction with these protein bands showed that in BBM isolated from dexamethasone treated rats there was a 2.5 -fold decrease in the staining intensity when compared to BBM isolated from control rats. The staining pattern is specific since these protein bands were not visualized in the presence of preimmune serum and were completely protected by antigenic peptide (13). As a control the same BBM were analyzed for the presence of ecto- 5 '-nucleotidase by Western blots. Densitometric analysis of the staining intensity showed no difference in BBM isolated from dexamethasone treated vs control rats.

The effect of dexamethasone on BBM lipid composition. Dexamethasone caused significant changes in BBM lipid composition. Dexamethasone increased glucosylceramide mass content $(528 \pm 63$ in dexamethasone vs. $312 \pm 41 \mathrm{ng} / \mathrm{mg}$ BBM protein in control, $P<0.02$ ). Dexamethasone also caused significant alterations in neutral glycosphingolipid species, in that there are increases in the relative amounts of hydroxylated and/ or phytosphingosine containing glucosylceramide species ( $\mathrm{Ta}-$ ble III). Dexamethasone caused significant alterations in phospholipid species as well, including an increase in sphirgomye- 


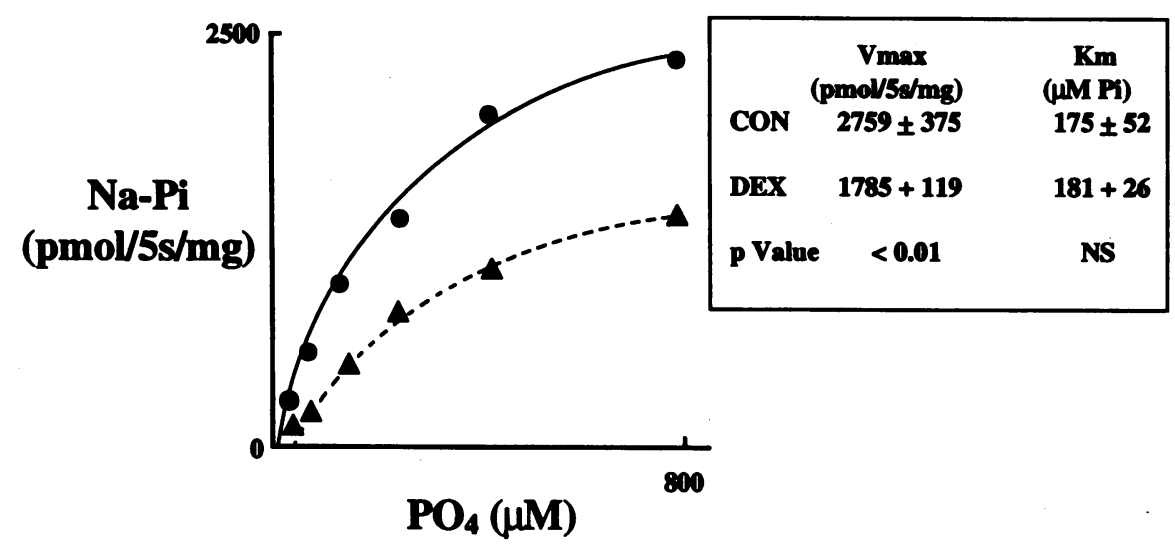

Figure 2. Effect of dexamethasone on BBM $\mathrm{Na}-\mathrm{Pi}$ cotransport kinetics as a function of extravesicular phosphate. The kinetic parameters were calculated by nonlinear curve fitting assuming Michaelis Menton kinetics (Enzfitter, Biosoft, UK). The data are expressed as the mean \pm SE for 6 BBM in each group. lin, a decrease in phosphatidylcholine, resulting in an increase in the sphingomyelin to phosphatidylcholine mole ratio (Table IV). Dexamethasone had no effect on phosphatidylethanolamine, phosphatidylserine, or phosphatidylinositol mole content (Table IV). In addition, dexamethasone also did not significantly alter cholesterol $(360.7 \pm 8.4$ in dexamethasone vs. $356.8 \pm 22.1 \mathrm{nmol} / \mathrm{mg} \mathrm{BBM}$ protein in control, $P=\mathrm{NS}$ ), total phospholipid (485.5 \pm 10.3 in dexamethasone vs $450.7 \pm 13.6$ nmole/mg BBM protein in control, $P=\mathrm{NS}$ ) mole content, or the cholesterol to phospholipid mole ratio $(0.75 \pm 0.02$ in dexamethasone vs. $0.79 \pm 0.04$ with control, $P=. \mathrm{NS})$.

The effect of dexamethasone on BBM fluidity. Dexamethasone increased the steady-state fluorescence anisotropy of DPH (Fig. 5 left). Dexamethasone also significantly increased the fluorescence lifetime of DPH. DPH lifetime data in biological membranes is best fitted assuming a Lorentzian distribution rather than a single or multiple discrete lifetime components

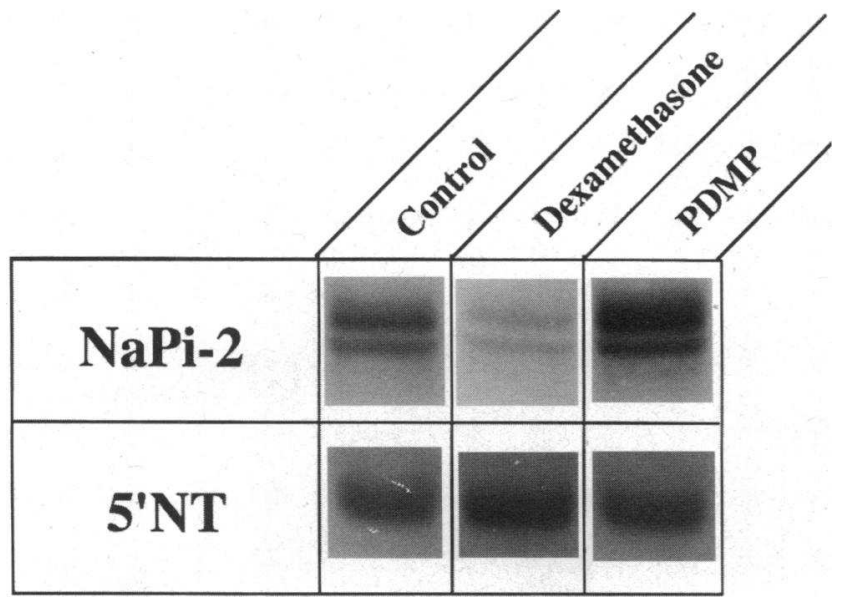

Figure 3. Northern blot analysis of RNA isolated from control, dexamethasone, and PDMP treated rats. After electrophoresis RNA was transferred to membranes and hybridized sequentially with $\mathrm{NaPi}-2$, GAPDH, and $\beta$-actin cDNA probes. The mRNA bands corresponding to $\mathrm{NaPi}-2, \mathrm{GAPDH}$, and $\beta$-actin were quantitated by densitometry. $\mathrm{NaPi}-2 / \mathrm{GAPDH}$ mRNA relative density (mean $\pm \mathrm{SEM}, \boldsymbol{n}$

$=6: 1.000 \pm 0.051$ in control, $0.373 \pm 0.046$ in dexamethasone, $P<0.01$, and 1.010 \pm 0.066 in PDMP $(P=$ NS compared to control $)$. NaPi-2/ $\beta$ actin mRNA relative density (mean \pm SEM, $n=6: 1.028 \pm 0.095$ in control, $0.462 \pm 0.043$ in dexemethasone, $P<0.001$, and $1.037 \pm 0.130$ in PDMP ( $P=$ NS compared to control $)$.
(36). There was a significant increase in the center (9.94 in control vs. $10.50 \mathrm{~ns}$ in dexamethasone, $P<0.01$ ), and a significant decrease in the width (1.60 in control vs. 0.93 ns in dexamethasone, $P<0.01$ ) of the lifetime distribution of DPH in BBM isolated from dexamethasone-treated rats (Fig. $6 A$ ). Dexamethasone also significantly decreased the rotational diffusion of DPH as measured by the dynamic polarization of DPH. Dexamethasone caused an increase in the limiting anisotropy, and caused decreases in the fast and slow rotational diffusion rate of DPH within the BBM lipid bilayer (Table V).

Dexamethasone also increased the generalized polarization of the phase sensitive fluorescence probe Laurdan (Fig. 5 right). Dexamethasone caused a significant increase in the center (4.33 in control vs. $4.58 \mathrm{~ns}$ in dexamethasone, $P<0.05$ ) and a significant decrease in the width $(0.43$ in control vs. $0.15 \mathrm{~ns}$ in dexamethasone, $P<0.01$ ) of the lifetime distribution of Laurdan (Fig. $6 B$ ). The steady-state and lifetime measurements with DPH (rotational probe) and Laurdan (phase-sensitive probe),

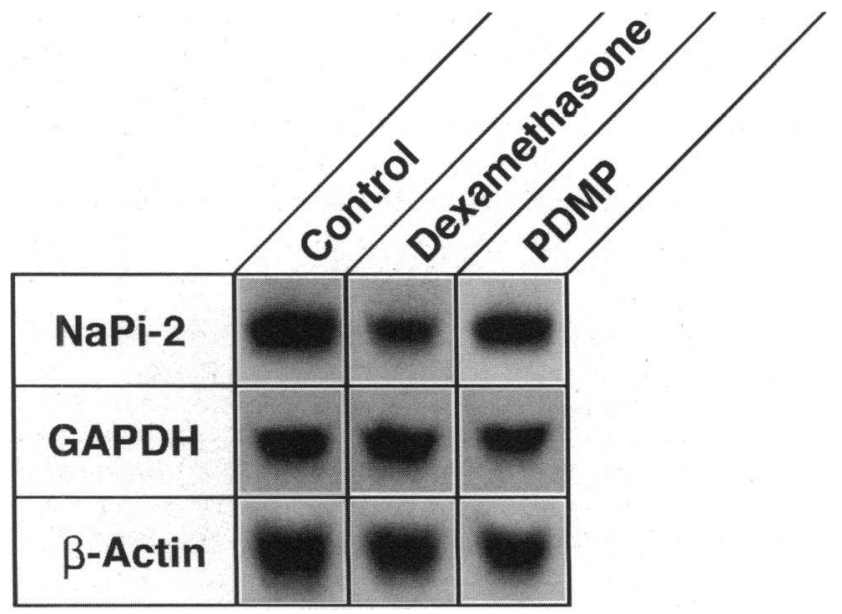

Figure 4. Western blot analysis of BBM isolated from control, dexamethasone, and PDMP-treated rats. After SDS-polyacrylamide gel electrophoresis BBM proteins were transferred to membranes, and probed with antisera to $\mathrm{Na}-\mathrm{Pi}$ cotransport system ( $\mathrm{NaPi}-2)$ and ecto-5' - nucleotidase ( $\left.5^{\prime} \mathrm{NT}\right)$. Protein bands corresponding to NaPi-2 and $5^{\prime} \mathrm{NT}$ were quantitated by densitometry. NaPi-2 relative density (mean \pm SEM, $n$ $=6: 1.00 \pm 0.14$ in control, $0.39 \pm 0.10$ in dexamethasone, $P<0.01$, and $1.55 \pm 0.18$ in PDMP $(P<0.01$ compared to control $)$. 


\begin{tabular}{lrrr}
\hline & Control & Dexamethasone & $P$ value \\
\hline & mole $\%$ & mole $\%$ & \\
Nonhydroxy fatty acid - C18 sphingosine containing glucosylceramide & $33.7 \pm 2.9$ & $12.2 \pm 0.4$ & $<0.01$ \\
Nonhydroxy fatty acid - C18 phytosphingosine containing glucosylceramide & $8.3 \pm 1.3$ & $15.9 \pm 1.3$ & $<0.01$ \\
Hydroxy fatty acid - glucosylceramide and galactosylceramide & $30.4 \pm 3.7$ & $45.2 \pm 1.9$ & $<0.01$ \\
Nonhydroxy fatty acid - C18 sphingosine containing galactosylceramide & $4.8 \pm 0.6$ & $10.3 \pm 0.5$ & $<0.01$ \\
Nonhydroxy fatty acid - C18 sphingosine containing lactosylceramide & $9.3 \pm 0.5$ & $6.7 \pm 1.2$ & $<0.01$ \\
Nonhydroxy fatty acid - C18 phytosphingosine containing globotetraglycosylceramide & $6.0 \pm 0.4$ & $3.0 \pm 0.5$ & $<0.01$ \\
Hydroxy fatty acid - C18 sphingosine containing globotetraglycosylceramide & $6.3 \pm 0.4$ & $6.2 \pm 0.6$ & NS \\
\hline
\end{tabular}

The data are expressed as the mean \pm SE for 6 BBM in each group.

therefore, indicate that dexamethasone causes a decrease in BBM lipid fluidity.

The effect of PDMP on BBM glucosylceramide content and $\mathrm{Na}-\mathrm{Pi}$ cotransport activity. The administration of the glucosylceramide synthase inhibitor PDMP to control rats significantly decreased glucosylceramide content $(199 \pm 19$ with PDMP vs. $312 \pm 41 \mathrm{ng} / \mathrm{mg} \mathrm{BBM}$ protein in control, $P<0.02$ ). The effect of PDMP on glucosylceramide content was quite specific as PDMP caused no changes in BBM cholesterol, total phospholipid, sphingomyelin, or phosphatidylcholine content (Table VI). The effect of PDMP to lower BBM glucosylceramide content was associated with a significant increase in BBM NaPi cotransport activity (Fig. 7). The effect of PDMP was specific and selective for $\mathrm{Na}-\mathrm{Pi}$, as PDMP did not significantly alter Na-glucose or Na-proline cotransport activities (Fig. 7). The effect of PDMP to increase BBM Na-Pi cotransport activity was associated with a 1.5-fold increase in $\mathrm{BBM} \mathrm{NaPi-2}$ protein abundance (Fig. 4). Interestingly, the increase in $\mathrm{NaPi}-2$ protein abundance was not associated with an increase in $\mathrm{NaPi}-2$ mRNA abundance (Fig. 3). The effect of PDMP to lower BBM glucosylceramide content was also associated with an increase in BBM lipid fluidity, as reflected by a significant decrease in the steady-state fluorescence anisotropy of DPH (Fig. 8).

\section{Discussion}

This study demonstrates that dexamethasone selectively inhibits BBM Na-Pi cotransport activity, an effect mediated by a de-

Table IV. The Effect of Dexamethasone on Brush Border Membrane Phospholipid Composition

\begin{tabular}{lcc}
\hline & Control & Dexamethasone \\
\hline & mole \% & mole \% \\
Sphingomyelin & $40.2 \pm 0.9$ & $44.0 \pm 1.1^{\ddagger}$ \\
Phosphatidylcholine & $28.8 \pm 0.9$ & $26.5 \pm 0.9^{*}$ \\
Sphingomyelin phosphatidylcholine & $1.43 \pm 0.06$ & $1.70 \pm 0.08^{\ddagger}$ \\
Phosphatidylethanolamine & $20.7 \pm 1.7$ & $18.8 \pm 2.2$ \\
Phosphatidylserine & $9.8 \pm 0.7$ & $10.7 \pm 0.8$ \\
Phosphatidylinositol & $3.0 \pm 0.2$ & $2.6 \pm 0.1$ \\
& &
\end{tabular}

The data are expressed as the mean \pm SE for $12 \mathrm{BBM}$ in each group. ${ }^{*} P<0.05,{ }^{\ddagger} P<0.01$ by unpaired $t$ test. crease in the $V_{\max }$. There was no change in the affinities of the transporter for $\mathrm{Na}$ or $\mathrm{Pi}$. These results agree with previous studies also showing that the inhibitory effect of dexamethasone on $\mathrm{NaPi}$ cotransport is independent of endogenous parathyroid hormone activity and of dietary $\mathrm{Pi}$ content $(6,8)$.

The decrease in $V_{\max }$ of renal cortical BBM NaPi cotransport in dexamethasone treated rats correlated with parallel decreases in renal cortical NaPi-2 mRNA content and renal cortical BBM $\mathrm{NaPi}-2$ protein abundance. The decreases in transcription and translation of Na-Pi cotransporter plays an important role in the dexamethasone induced inhibition of $\mathrm{Na}-\mathrm{Pi}$ cotransport. Since in a previous study actinomycin D and cycloheximide blocked the inhibition of Na-Pi cotransport, it is possible that dexamethasone may activate a regulatory protein which then inhibits $\mathrm{Na}$ $P i$ specific transcription and translation.

The decrease in the $V_{\max }$ of Na-Pi cotransport also correlated with increases in BBM glucosylceramide and sphingomyelin content. Dexamethasone was shown to increase the sphingomyelin content of 3T3-L1 and HeLa cells by increasing the rate of sphingomyelin synthesis from phosphatidylcholine $(38,39)$. The present study is the first to determine the effect of dexamethasone on renal BBM sphingomyelin composition. We found that dexamethasone increased sphingomyelin content by 9.3\%. This was paralleled by an $8.0 \%$ decrease in phosphatidylcholine content. These results are compatible with observations on many cell lines, including the kidney, that sphingomyelin is

\section{$\mathbf{r}_{\mathrm{DPH}}$}

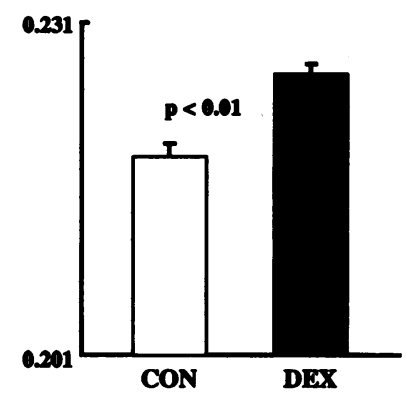

GP LaURdan

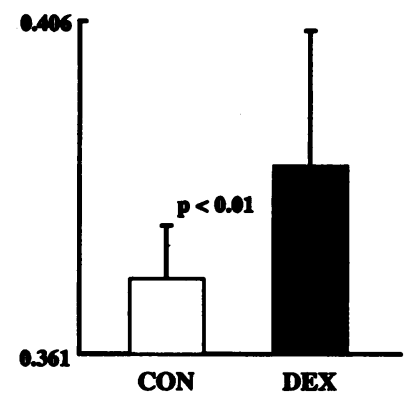

Figure 5. Effect of dexamethasone on the steady-state fluorescence anisotropy of diphenylhexatrine $\left(\mathrm{r}_{\mathrm{DPH}}\right)$ and generalized polarization of Laurdan $\left(\mathrm{GP}_{\mathrm{Laurdan}}\right)$. Increased $\mathrm{r}_{\mathrm{DPH}}$ or $\mathrm{GP}_{\text {Lurdan }}$ reflect a lower BBM lipid fluidity. The data are expressed as the mean \pm SE for 12 BBM in each group. 

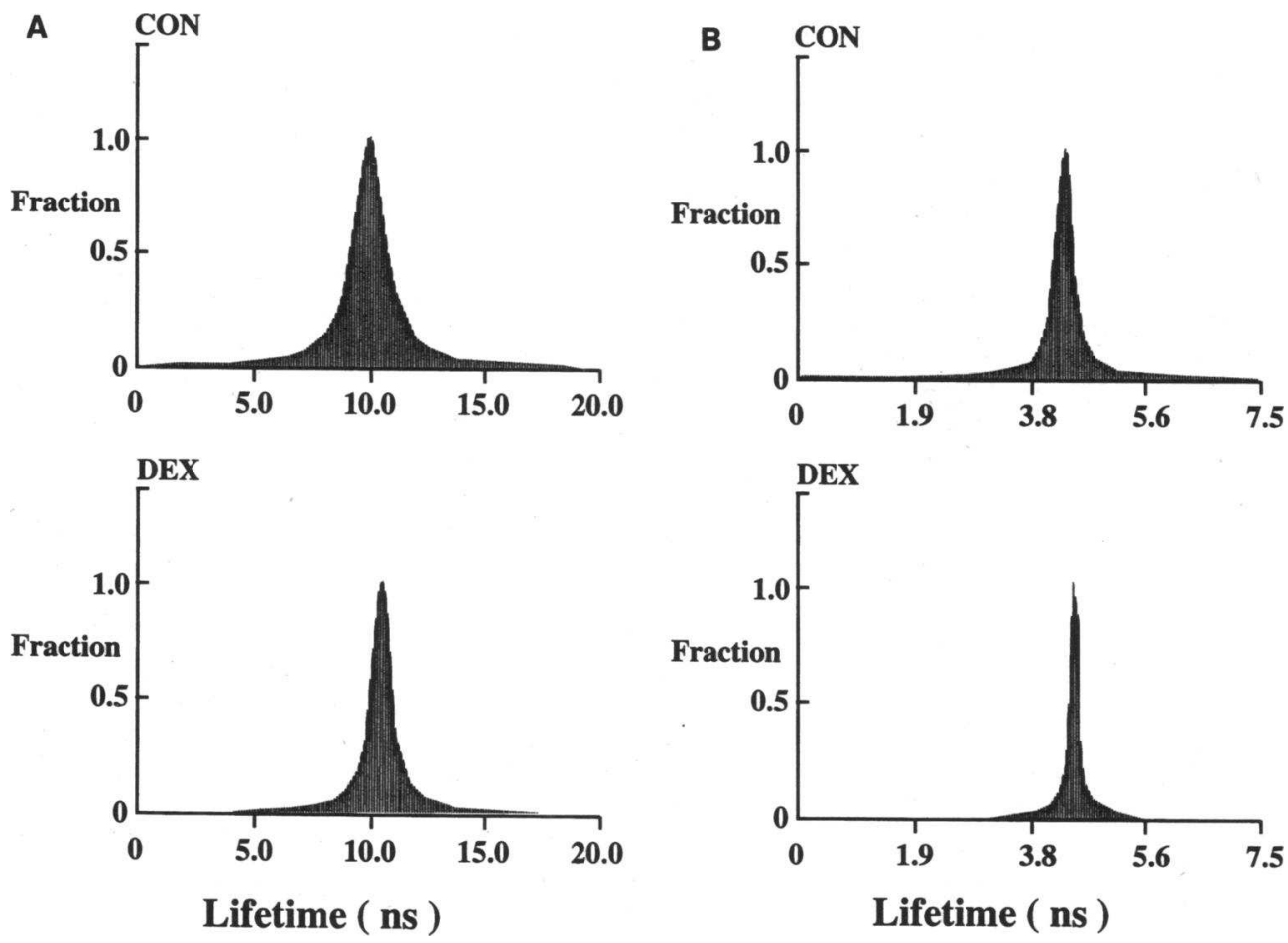

Figure 6. Effect of dexamethasone on the fluorescence lifetime distribution of $(A)$ DPH and $(B)$ Laurdan. Dexamethasone causes an increase in the center and a decrease in the width of the fluorescence lifetime distributions of DPH, and Laurdan.

synthesized from phosphatidylcholine by the addition of ceramide $(40,41)$. Also, we and others have found that an alteration in BBM sphingomyelin content is associated with a similar but opposite change in phosphatidylcholine content $(17,18)$. The net result is no overall change in the sum total of BBM sphingomyelin plus phosphatidylcholine content.

Dahiya and Brasitus had reported that dexamethasone increased rat renal cortical and medullary total neutral glycosphingolipid content (42). In our study, we specifically measured the effect of dexamethasone on superficial cortical BBM glucosylceramide content since we were interested in correlating the effects of dexamethasone on BBM Na-Pi cotransport with the potential effects of dexamethasone on BBM glycosphingolipid composition. Our study does not determine whether the effect of dexamethasone to increase glucosylceramide content is mediated by increased rate of synthesis or decreased rate of degradation of glucosylceramide (15). Dexamethasone enhances gluconeogenesis in rat kidney cortex (8). Increased gluconeogenesis may increase UDP-glucose, providing increased substrate for

Table V. The Effect of Dexamethasone on the Rotational Diffusion Rate of Lipids as Revealed by the Dynamic Polarization of DPH

\begin{tabular}{lccc}
\hline & $D_{1}$ & $D_{2}$ & $r_{\infty}$ \\
\hline & $10^{-1 / n s}$ & $10^{-4} / n s$ & \\
Control & $2.71 \pm 0.25$ & $15.51 \pm 1.64$ & $0.183 \pm 0.001$ \\
Dexamethasone & $1.87 \pm 0.23^{*}$ & $9.52 \pm 0.35^{\ddagger}$ & $0.194 \pm 0.002^{\ddagger}$ \\
& & & \\
\hline
\end{tabular}

The data are expressed as the mean \pm SEM for 6 BBM in each group. ${ }^{*} P<0.05,{ }^{\ddagger} P<0.01$ by unpaired $t$ test. The dynamic polarization data was analyzed by the Globals Unlimited software. $D_{1}$, the fast rotational diffusion rate of DPH; $D_{2}$, the slow rotational diffusion rate of DPH; $r_{\infty}$, the limiting anisotropy; $D P H$, diphenylhexatriene. glucosylceramide synthesis (15), even in the absence of changes in the activities of glucosylceramide synthase or glucosylceramide $\beta$-glucosidase. These later enzymes regulate glucosylceramide synthesis and hydrolysis, respectively (15). Dahiya and Brasitus had reported that dexamethasone increased the concentration of neutral glycosphingolipids and the short chain hydroxy fatty acids of glucosylceramide. While these data are not directly comparable to those presented here in that a different strain of rats (Sherman vs. Sprague Dawley) was used and total kidney rather than cortical BBM was analyzed, the data are, nevertheless, consistent in that there appears to be an increase in the hydroxylated neutral glycosphingolipid species following dexamethasone (42). Interestingly, in addition to the effect of increased levels of sphingomyelin, an increase in the relative amounts of the more polar hydroxylated glycosphingolipid species would also be expected to cause a decrease in membrane fluidity (43).

Our study indicates that the dexamethasone induced increase

Table VI. The Effect of PDMP on Brush Border Membrane Lipid Composition

\begin{tabular}{lcc}
\hline & Control & PDMP \\
\hline $\begin{array}{l}\text { Cholesterol } \\
\text { (nmol/mg BBM protein) }\end{array}$ & $422.8 \pm 5.7$ & $419.7 \pm 6.3$ \\
$\begin{array}{l}\text { Total Phospholipid } \\
\text { (nmol/mg BBM protein) }\end{array}$ & $464.9 \pm 10.2$ & $456.1 \pm 4.0$ \\
$\begin{array}{l}\text { Sphingomyelin } \\
\text { (mole \%) }\end{array}$ & $41.6 \pm 0.6$ & $40.5 \pm 1.3$ \\
$\begin{array}{c}\text { Phosphatidylcholine } \\
\text { (mole \%) }\end{array}$ & $20.5 \pm 0.4$ & $19.8 \pm 0.5$ \\
\hline
\end{tabular}

The data are expressed as the mean $\pm \mathrm{SE}$ for $6 \mathrm{BBM}$ in each group. 

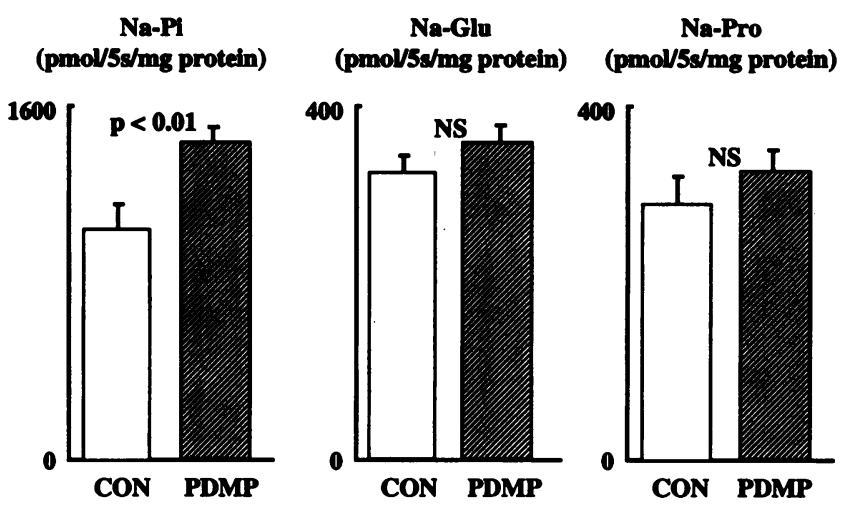

Figure 7. Effect of the glucosylceramide synthase inhibitor PDMP on $B B M$ transport activity. The data are expressed as the mean $\pm S E$ for 12 BBM in each group.

in BBM glucosylceramide content is correlated with a selective decrease in Na-Pi cotransport. On the other hand, in rats treated with the glucosylceramide synthase inhibitor PDMP, the decrease in BBM glucosylceramide content is associated with a selective increase in BBM Na-Pi cotransport activity. Thus, our studies establish an inverse correlation between BBM glucosylceramide content and BBM Na-Pi cotransport activity (Fig. 9). Furthermore, there is also an inverse correlation between BBM glucosylceramide content and BBM NaPi-2 protein abundance. Our results therefore suggest that the dexamethasone induced alteration in BBM glucosylceramide content and/or other related glycosphingolipids may mediate the inhibitory effect of dexamethasone on Na-Pi cotransport activity and BBM $\mathrm{NaPi}-2$ protein abundance.

At the present time it is not known how alterations in BBM lipid composition modulate Na-Pi cotransport activity. Recent studies indicate that alterations in glycosphingolipid content control cellular functions by diverse mechanisms. In several cell types 1,25 dihydroxy vitamin $\mathrm{D}_{3}$, TNF- $\alpha$, and $\gamma$-inferferon have been shown to induce hydrolysis of membrane sphingomyelin and generation of ceramide (44-46). Ceramide has been shown to have diverse second messenger functions including (a) ceramide-activated protein kinase and phosphatase, (b) phosphorylation of the epidermal growth factor receptor, (c) activation of Raf, MEK, MAP kinase and phospholipase $A_{2},(d)$ degradation of $\mathrm{IkB}$, the physiologic inhibitor of the transcription factor NK-kB, with subsequent translocation to the nucleus, and

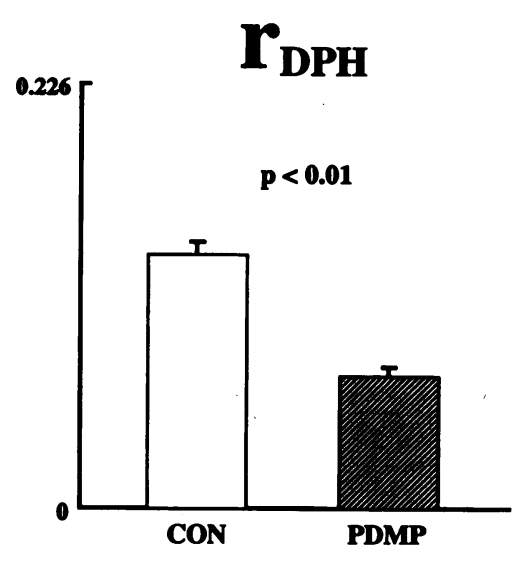

Figure 8. Effect of PDMP on BBM steadystate fluorescence anisotropy of DPH $\left(\mathrm{r}_{\mathrm{DPH}}\right)$. The data are expressed as the mean $\pm S E$ for $12 \mathrm{BBM}$ in each group.
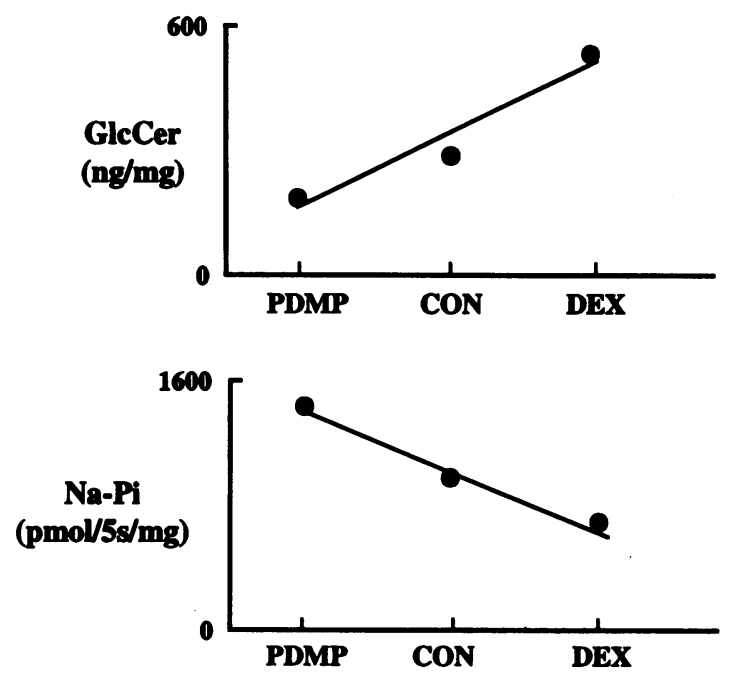

Figure 9. An inverse relationship between BBM glucosylceramide ( $\mathrm{GlcCer}$ ) content and Na-Pi cotransport activity in BBM from PDMP treated rats, control (Con) rats, and Dexamethasone (Dex)-treated rats.

(e) downregulation of c-myc expression (44-47). In addition, glycosphingolipids may also modulate protein delivery from the endoplasmic reticulum-golgi complex to the plasma membrane. In baby hamster kidney cells, inhibition of glucosylceramide synthase with PDMP markedly decreases plasma membrane glucosylceramide content and also impairs plasma membrane delivery of the vesicular stomatitis virus G (VSV-G) protein (48). Therefore, glycophinglipids can modulate cell function by transcriptional/translational as well as posttranslational mechanisms. Our data indicates that in dexamethasone treated rats the increase in BBM glucosylceramide content is correlated with decreases in $\mathrm{NaPi}-2$ mRNA and $\mathrm{NaPi}-2$ protein abundance. In contrast, in PDMP treated rats the decrease in BBM glucosylceramide content is correlated with an increase in $\mathrm{NaPi}-2$ protein abundance, independent of changes in $\mathrm{NaPi}$ 2 mRNA abundance.

Alterations in BBM lipid composition could also alter the lipid mobility and/or the lipid dynamics which could in turn modulate Na-Pi cotransport activity (11). In our study, we found dexamethasone induced increases in BBM glucosylceramide and sphingomyelin content were associated with significant changes in steady-state anisotropy, lifetime distribution, and rotational diffusion rate of the fluorescent probe DPH, as well as significant changes in the emission spectra and lifetime of the phase-sensitive fluorescent probe Laurdan. These changes indicate that dexamethasone causes less "fluid" and/or more "ordered or gel-like" microenvironments in the BBM lipid bilayer (29). In agreement with our previous findings (11) these changes are associated with a selective modulation of $\mathrm{Na}$ $\mathrm{Pi}$ cotransport, while there are no changes in Na-glucose or Na-proline cotransport activities. The effects of increases in membrane glycosphingolipid content and/or dexamethasone administration to decrease membrane fluidity occurs in several (49-51), but not all (52-54) cells of non-renal origin. The effect of PDMP to decrease BBM glucosylceramide content and increase BBM Na-Pi cotransport activity, on the other hand, is associated with an increase in BBM fluidity. Thus, in addition to the inverse correlation between BBM glucosylceramide content and BBM Na-Pi cotransport activity (Fig. 9), there is also 
a direct correlation between BBM fluidity and BBM Na-Pi cotransport activity.

In summary, these studies indicate that dexamethasone induced decrease in the $V_{\max }$ of BBM Na-Pi cotransport is correlated with decreases in renal cortical NaPi-2 mRNA and BBM $\mathrm{NaPi}-2$ protein abundance, and with an increase in BBM glycosphingolipid content. Since primary alteration in BBM glucosylceramide content selectively modulates BBM Na-Pi cotransport activity and $\mathrm{NaPi}-2$ protein abundance, we propose that the dexamethasone induced increase in BBM glucosylceramide content, or a closely related glycosphingolipid, plays an important role in mediating the inhibitory effect of dexamethasone on Na-Pi cotransport activity.

\section{Acknowledgments}

The authors dedicate this manuscript to the beloved memory of the late Sonja $\mathrm{K}$. Gross who has always been and will continue to be a source of inspiration to all of us.

The authors thank Drs. Dave M. Jameson (University of Hawaii, Honolulu, HI) and Enrico Gratton (Laboratory for Fluorescence Dynamics, University of Illinois, Urbana-Champaign, IL) for the use of their spectrofluorometers and laboratories for fluorescence lifetime and dynamic polarization measurements, Sandra F. Nickerson and Julie Propes for their secretarial assistance, and the Biomedical Media Service at the Dallas VAMC for the illustrations.

This work was supported by grants from Department of Veterans Affairs Merit Review (M. Levi and J. A. Shayman), National Institutes of Health grants DK-41487 (J. A. Shayman) and NS-15037 (R. H. McCluer), Swiss National Science Foundation grants 32.28664.90 (J. Biber), and 32.30785.91 (H. Murer), and in part by the Department of Mental Retardation of the Commonwealth of Massachusetts, Contract No. $100220023 S C$. J. A. Shayman is an Established Investigator of the American Heart Association.

\section{References}

1. Roberts, K. E., and R. F. Pitts. 1953. The effect of cortisone and desoxycorticosterone on the renal tubular reabsorption of phosphate and the excretion of titratable acid and potassium in dogs. Endocrinology. 52:324-330.

2. Laron, Z., J. D. Crawford, and R. Klein. 1957. Phosphaturic effect of cortisone in normal and parathyroidectomized rats. Proc. Soc. Exp. Biol. Med. 96:649-651.

3. Anderson, J., and J. B. Forster. 1959. Effect of cortisone on urinary phosphate excretion in man. Clin. Sci. 18:437-439.

4. Frick, A., and I. Durasin. 1980. Proximal tubular reabsorption of inorganic phosphate in adrenalectomized rats. Pflügers Arch. 385:189-192.

5. Webster, S. K., A. Haramati, and F. G. Knox. 1986. Effect of dexamethasone on segmental phosphate reabsorption in phosphate-deprived rats. Am. J. Physiol. 251:F576-F580.

6. Frick, A., I. Durasin, and M. Neuweg. 1984. Glucocorticoid-induced inhibition of the reabsorption of inorganic phosphate in the proximal tubule in the absence of parathyroid hormone. Adv. Exp. Med. Biol. 178:81-86.

7. Freiberg, J. M., J. Kinsella, and B. Sacktor. 1982. Glucocorticoids increase the $\mathrm{Na}^{+}-\mathrm{H}^{+}$exchange and decrease the $\mathrm{Na}^{+}$gradient-dependent phosphate-uptake systems in renal brush border membrane vesicles. Proc. Natl. Acad. Sci. USA. 79:4932-4936.

8. Turner, S. T., G. M. Kiebzak, and T. P. Dousa. 1982. Mechanism of glucocorticoid effect on renal transport of phosphate. Am. J. Physiol. 243:C227C236.

9. Poujeol, P., and A. Vandewalle. 1985. Phosphate uptake by proximal cells isolated from rabbit kidney: role of dexamethasone. Am. J. Physiol. 249:F74F83.

9a. Boross, M., J. Kinsella, L. Cheng, and B. Sacktor. 1986. Glucocorticoids and metabolic acidosis-induced renal transports of inorganic phosphate, calcium, and $\mathrm{NH}_{4}$. Am. J. Physiol. 250:F827-F833.

10. Noronha-Blob, L., and B. Sacktor. 1986. Inhibition by glucocorticoids of phosphate transport in primary cultured renal cells. J. Biol. Chem. 261:21642169.

11. Levi, M., B. M. Baird, and P. V. Wilson. 1990. Cholesterol modulates rat renal brush border membrane phosphate transport. J. Clin. Invest. 85:231-237.
12. Magagnin, S., A. Werner, D. Markovich, V. Sorribas, G. Stange, J. Biber, and $\mathrm{H}$. Murer. 1993. Expression cloning of human and rat renal cortex Na-Pi cotransport. Proc. Natl. Acad. Sci. USA. 90:5979-5983.

13. Custer, M., M. Lotscher, J. Biber, H. Murer, and B. Kaissling. 1994. Expression of Na-Pi cotransport in rat kidney: localization by RT-PCR and immunohistochemistry. Am. J. Physiol. 35:767-774.

14. Fiske, C. H., and Y. Subbarow. 1925. The colorimetric determination of phosphorus. J. Biol. Chem. 66:375-400.

15. Shayman, J. A., and N. S. Radin. 1991. Structure and function of renal glycosphingolipids. Am. J. Physiol. 260:F291-F302.

16. Zador, I. Z., G. D. Deshmukh, R. Kunkel, K. Johnson, N. S. Radin, and J. A. Shayman. 1993. A role for glycosphingolipid accumulation in the renal hypertrophy of streptozotocin-induced diabetes mellitus. J. Clin. Invest. 91:797803.

17. Levi, M., D. M. Jameson, and B. Wieb van der Meer. 1989. Role of BBM lipid composition and fluidity in impaired renal Pi transport in aged rat. Am. J. Physiol. 256:F85-F94.

18. Levi, M. 1990. Heterogeneity of Pi transport by BBM from superficial and juxtamedullary cortex of rat. Am. J. Physiol. 258:F1616-F1624.

19. Lowry, O. H., N. J. Rosebrough, A. L. Farr, and R. J. Randall. 1951. Protein measurement with the Folin phenol reagent. J. Biol. Chem. 193:265-275.

20. Laemmli, U. K. 1970. Cleavage of structural proteins during the assembly of the head of bacteriophage T4. Nature (Lond.). 227:680-685.

21. Levi, M., M. Arar, B. Kaissling, H. Murer, and J. Biber. 1993. Low Pi diet increases the abundance of an apical protein related to $\mathrm{Na}-\mathrm{Pi}$ cotransport in rat proximal tubular S3 segments. Eur. J. Physiol. (Molecular and Cellular Physiology). 426:5-11.

22. Dawson, T. P., R. Gandhi, M. Le Hir, and B. Kaissling. 1989. Ecto-5'nucleotidase: localization by light microscopic histochemistry and immunohistochemistry methods in the rat kidney. J. Histochem. Cytochem. 37:39-47.

23. Bligh, E. G., and W. J. Dyer. 1959. A Rapid Method of Total Lipid Extraction and Purification. Can. J. Biochem. Physiol. 37:911-917.

24. Esko, J. D., and C. R. H. Raetz. 1980. Mutants of chinese hamster ovary cells with altered membrane phospholipid composition. J. Biol. Chem. 255:44744480 .

25. Ames, B. N., and D. T. Dubin. 1960 . The Role of Polyamines in the Neutralization of Bacteriophage of Deoxyribonucleic Acid. J. Biol. Chem. 235:769-775.

26. Folch, J., M. Lees, and G. H. Sloane Stanley. 1957. A simple method for the isolation and purification of total lipids from animal tissues. J. Biol. Chem. 226:497-509.

27. McCluer, R. H., M. D. Ullman, and F. B. Jungalwala. 1989. High-performance liquid chromatography of membrane lipids: glycosphingolipids and phospholipids. Methods Enzymol. 172:538-575.

28. Parasassi, T., G. De Stasio, G. Ravangnan, R. M. Rusch, and E. Gratton. 1991. Quantitation of lipid phases in phospholipid vesicles by the generalized polarization of Laurdan fluorescence. Biophys. J. 60:179-189.

29. Levi, M., P. Wilson, O. J. Cooper, and E. Gratton. 1993. Lipid phases in renal brush border membranes revealed by laurdan fluorescence. Photochem. and Photobiol. 57:420-425.

30. Jameson, D. M., and T. L. Hazlett. 1991. Time-resolved fluorescence in biology and biochemistry. In Biophysical and Biochemical Aspects of Fluorescence Spectroscopy. T. Gregory Dewey, editor. Plenum Press, New York. 105133.

31. Beechem, J. M., E. Gratton, M. Ameloot, J. R. Knutson, and L. Brand. 1991. The global analysis of fluorescene intensity and anisotropy decay data: second-generation theory and programs. In Topics in Fluorescence Spectroscopy. Vol 2. Joseph R. Lakowicz, editor. Plemum Press, New York. 241-305.

32. Chomczynski, P., and N. Sacchi. 1987. Single-step method of RNA isolation by acid guanidinium thiocyanate-phenol-chloroform extraction. Anal. Biochem. 162:156-159.

33. Farrell, E., Jr. 1990. Methodologies for RNA characterization II: quantitation by Northern blot analysis and S1 nuclease assay. Clin. Biotechnol. 2:107119.

34. Cleveland, D. W., M. A. Lopata, R. J. Macdonald, N. J. Cowman, W. J. Rutter, and M. W. Kirschner. 1980. Number and evolutionary conservation of $\alpha$ and $\beta$-tubulin and cytoplasmic $\beta$ - and r-actin genes using specific cloned cDNA probes. Cell. 20:95-105.

35. Fort, P. h., L. Marty, M. Piechaczyk, S. El-Sabrouty, C. H. Dani, P. H. Jeanteur, and J. M. Blanchard. 1985. Various rat adult tissues express only one major mRNA species from the glyceraldehyde-3-phosphate-dehydrogenasemultigenic family. Nucleic Acids. Res. 13:1431-1442.

36. Kinsella, J. L. 1990. Action of glucocorticoids on proximal tubule transport systems. Semin. Nephrology. 10:330-338.

37. Fiorini, R., M. Valentino, S. Wang, M. Glaser, and E. Gratton. 1987. Fluorescence lifetime distributions of 1,6-Diphenyl-1,3,5-hexatriene in phospholipid vesicles. Biochemistry. 26:3864-3870.

38. Johnston, D., E. R. Matthews, and G. Melnykovych. 1980. Glucocorticoid effects on lipid metabolism in HeLa cells: inhibition of cholesterol synthesis and increased sphingomyelin synthesis. Endocrinology. 107:1482. 
39. Nelson, D. H., and D. K. Murray. 1982. Dexamethasone increases the synthesis of sphingomyelin in 3T3-L1 cell membranes. Proc. Natl. Acad. Sci. USA. 79:6690-6692.

40. Voelker, D. R., and E. P. Kennedy. 1982. Cellular and enzymic synthesis of sphingomyelin. Biochemistry. 21:2753-2759.

41. Allan, D., and P. Quinn. 1988. Resynthesis of sphingomyelin from plasmamembrane phosphatidylcholine in BHK cells treated with Staphylococcus aureus sphingomyelinase. Biochem. J. 254:765-771.

42. Dahiya, R., and T. A. Brasitus. 1988. Dexamethasone-induced alterations in the glycosphingolipids of rat kidney. Lipids. 23:863-868.

43. Curatolo, W. 1987. The physical properties of glycolipids. Biochim. Biophys. Acta. 906:11-136.

44. Hannun, Y. A. 1994. The sphingomyelin cycle and the second messenger function of ceramide. J. Biol. Chem. 269:3125-3128.

45. Kolesnick, R., and D. W. Golde. 1994. The sphingomyelin pathway in tumor necrosis factor and interleukin-1 signaling. Cell. 77:325-238.

46. Liscovitch, M., and L. C. Cantley. 1994. Lipid second messengers. Cell. 77:329-334.

47. Schutze, S., K. Potthoff, T. Machleidt, D. Berkovic, K. Wiegmann, and M. Kronke. 1992. TNF activates NF-kB by phosphatidylcholine-specific phospholipase C-induced "acidic" sphingomyelin breakdown. Cell. 71:765-776.
48. Rosenwald, A. G., C. E. Machamer, and R. E. Pagano. 1992. Effects of a sphingolipid synthesis inhibitor on membrane transport through the secretory pathway. Biochemistry. 31:3581-3590.

49. Kiss, C., M. Balazs, and I. Keri-Fülöp. 1990. Dexamethasone decreases membrane fluidity of leukemia cells. Leukemia Res. 14:221-225.

50. Goins, B., M. Masserini, B. G. Barisas, and E. Freire. 1986. Lateral diffusion of ganglioside $\mathrm{G}_{\mathrm{M} 1}$ in phospholipid bilayer membranes. Biophys. $J$. 49:849-856.

51. Tsui, Z., W. Hou, L. Yang, and Z. Zhu. 1990. Effect of a cell differentiation inducer, ganglioside $\mathrm{GM}_{3}$, on the neutral glycosphingolipid composition and cel membrane fluidity of a human promyelocytic leukemia cell line HL-60. In Vivo. 4:205-208.

52. Dudeja, P. K., E. S. Foster, and T. A. Brasitus. 1987. Modulation of rat distal colonic brush-border membrane $\mathrm{Na}^{+}-\mathrm{H}^{+}$exchange by dexamethasone: role of lipid fluidity. Biochim. Biophys. Acta. 905:485-493.

53. Dudeja, P. K., R. Dahiya, M. D. Brown, R, and T. A. Brasitus. 1988. Dexamethasone influences the lipid fluidity, lipid composition and glycosphingolipid glycosyltransferase activities of rat proximal-small-intestinal Golgi membranes. Biochem. J. 253:401-408.

54. Keating, K. M., D. A. Roess, J. S. Peacock, and B. G. Barisas. 1985 Glucocorticoid effects on membrane lipid mobility during differentiation of murine B lymphocytes. Biochim. Biophys. Acta. 846:305-312. 